\title{
Pattern of morbidity and mortality among neonates admitted to neonatal intensive care unit in tertiary care centre, western Nepal.
}

\author{
Namrata KC* (ID), Bandana Shrestha, Arjun Bhattarai, Shankar Paudel, Nabraj Subedi \\ Department of Pediatrics Gandaki Medical College and Teaching Hospital, Pokhara, Nepal.
}

\begin{abstract}
Introduction: The neonatal period is the most vulnerable phase and the neonatal morbidity along with the mortality being the major health issues in the developing countries like Nepal. The objective of this study was to determine the pattern of diseases and their outcome in neonatal intensive care unit (NICU) as the common causes of mortality and morbidity in our region are preventable. Methods: This retrospective study was carried out in 1041 newborns admitted from 1st August 2019 to 30th July 2020 in Gandaki Medical College Teaching Hospital in Western Nepal. Age, sex, gestational age, diagnosis at admission, outcome of admitted newborns were the main variables under study. Data was entered and analyzed using SPSS version 20. Results: Among 1041 newborns, 599 (57.54\%) were male and 442 (42.46\%) were female, $1028(98.75 \%)$ were born in hospital while eight $(0.77 \%)$ were born at home and $5(0.48 \%)$ in ambulance. The majority 610 newborns (58.59\%) were admitted during the first 24 hours of life. Infection and hyperbilirubinemia were the main reasons for admission $(44.96 \%$ and $23.15 \%$ respectively), followed by prematurity $(9.51 \%)$ and birth asphyxia (9.13\%). A total of 831 (79.83\%) admitted newborns improved and discharged, 79 (7.59\%) were discharged on request, 61 (7.59\%) left against medical advice, 34 (3.26\%) were referred and 36 (3.46\%) expired. The major causes for neonatal mortality were prematurity (44.45\%), sepsis (27.78\%), and birth asphyxia (13.89\%). Among the expired neonates, 24 (66.67\%) were outborns and 12 (33.33\%) were inborns and majority 27 (75\%) expired at the age between 24 to 48 hours of life. Conclusions: Infection was the leading cause of morbidity and prematurity the leading cause of mortality in the NICU. This is preventable with antenatal care, training of manpower and procurement of necessary equipment.
\end{abstract}

Keywords: Morbidity, mortality, neonates, NICU

\section{*Correspondence:}

Dr. Namrata KC

Lecturer, Department of Pediatrics, Gandaki Medical College and Teaching Hospital, Pokhara, Nepal

Email: namukcpkr@gmail.com

Submitted: February 23, 2021

Accepted: May 31, 2021

To cite: KC N, Shrestha B, Bhandari A, Paudel S, Subedi N. Pattern of morbidity and mortality among neonates admitted to neonatal intensive care unit in tertiary care centre, Western Nepal. JGMC Nepal. 2021;14(1):24-8. DOI: $10.3126 /$ jgmcn.v14i1.35130

Phone: +977 9856035757

\section{INTRODUCTION}

Of the 130 million neonates born every year, about four million die in the first weeks of life globally. ${ }^{1}$ Most of the neonatal deaths (99\%) occur in the lower to middle income countries. The risk of newborn dying is 24 per 1000 live birth in first week of life, three per 1000 per week during the next first month and 0.12 per 1000 per week after the first year of life. ${ }^{2,3}$ The neonatal disease pattern is a sensitive indicator of availability, utilization and effectiveness of mother and child health services in the community. ${ }^{4}$ The efficient health care services of a country are categorized from neonatal morbidity and mortality. ${ }^{5,6}$ Neonatal period ( 0 to 28 days of life) is the most vulnerable time in which the newborn has to adapt to a totally new environment and is susceptible to many problems, which may even be life threatening. In spite of advances in perinatal and neonatal care, still the mortality rate of neonate is high, especially in developing country. ${ }^{7}$

The Nepal Demographic and Health Survey of 2016 found under five mortality rate of 39/1000 live births, infant mortality rate of 
$32 / 1000$ live births and neonatal mortality rate of $21 / 1000$ live births. ${ }^{8}$ In the developed countries, the main cause of morbidity and mortality in the neonatal period are congenital abnormalities which are mostly non-preventable, but in the developing countries the common causes such as infections, jaundice, birth asphyxia and pneumonia predominate. ${ }^{9}$ Most of the causes of morbidity and mortality in the neonatal period are preventable by proper antenatal care, early detection and treatment. ${ }^{10}$ These treatable causes vary from place to place and even from time to time in a particular point. ${ }^{11,12}$

After reduction in neonatal mortality rate (NMR), the goal is to reduce the morbidity of neonates by disease specific intervention. So, identifying the pattern of medical illness and the outcome in NICU will help the health care providers to plan service priorities.

\section{METHODS}

This was a retrospective cross-sectional study conducted in NICU at the Department of Pediatrics, in Gandaki Medical College (GMC), Nepal. The data details from August 2019 to July 2020 were retrieved from medical record section of hospital from October 2020. A total of 1041 neonates (both inborn and out-born), aged 0-28 days of life with all the required documents and admitted during this period were included in the study.

Neonatal Intensive Care Unit of GMC includes the facilities of mechanical ventilators, peripherally inserted cannula, bubble continuous positive airway pressure (CPAP), arterial blood gas monitoring, central oxygen and suction facilities, multichannel patient monitor, exchange transfusion and phototherapy. Data of all babies admitted were taken and analyzed. Variables were age at admission, gestational age, birth weight, gender, presenting complaints, complications, final diagnosis, outcome whether the newborn was improved and discharged after completion of treatment, discharged on request, left against medical advice, referred or expired. Data were entered and analyzed in SPSS version 20.

Ethical clearance: Ethical clearance was obtained from Institutional Review Committee of Gandaki Medical College.

\section{RESULTS}

The total number of neonates admitted during the study period was 1041. Male babies outnumbered their female counterpart with a ratio of 1.3:1. Both inborn and outborn neonates were admitted. Of the total admission, 1028
(98.75\%) were born in the hospital while $8(0.77 \%)$ were born at home and $5(0.48 \%)$ were born in ambulance. Regarding the maturity and birth weight of these babies, 99 (9.51\%) babies were premature with low birth weight (less than 2500 grams), 16 (1.54\%) newborns as macrosomia, $9(0.86 \%)$ newborns as intra-uterine growth retardation (IUGR) and 917 (88.08\%) had normal birth weight (Table 1). The majority of the newborns, 550 (52.83\%), were admitted during the first 24 hours of life (Table 2).

Table 1: Demographic data of newborns admitted.

\begin{tabular}{lcc}
\hline Variables & Frequency & Percent \\
Sex & 599 & 57.54 \\
Male & 442 & 42.46 \\
Female & 1041 & 100 \\
Total & & \\
Mode of Delivery & 1028 & 98.75 \\
Hospital & 8 & 0.77 \\
Home & 5 & 0.48 \\
Ambulance & & \\
Birth weight and maturity & & \\
Preterm LBW (low birth weight) & 83 & 7.97 \\
Preterm VLBW (very low birth weight) & 11 & 1.06 \\
Preterm ELBW (extremely low birth weight) & 5 & 0.48 \\
IUGR(intra-uterine growth retardation) & 917 & \\
Macrosomia & & \\
Normal weight & & \\
\hline & & \\
\hline
\end{tabular}

Table 2: Age at admission

\begin{tabular}{lcc}
\hline Age at admission & Frequency & Percent \\
0-24 hours of life & 550 & 52.83 \\
2-7 days & 288 & 27.66 \\
8-14 days & 75 & 7.2 \\
$>14$ days & 128 & 12.81 \\
\hline
\end{tabular}

The most common cause of admission was neonatal infection or the Sepsis (44.96\%). Next to sepsis, neonatal hyperbilirubinemia $(23.15 \%)$, prematurity $(9.51 \%)$ and perinatal asphyxia $(9.13 \%)$ were the common causes of admission to the neonatal unit (Table 3). Among neonatal sepsis, 293 newborns (28.15\%) were early onset sepsis and $175(16.81 \%)$ were late onset sepsis. A neonate having more than one morbidity is counted in each category. Hence the sum may be more than the total neonates in the study. 
Table 3: Causes of morbidity

\begin{tabular}{lcc}
\hline Diagnosis & Frequency & Percent \\
Sepsis & 468 & 44.96 \\
EONNS(early onset neonatal sepsis) & 293 & 28.15 \\
LONNS(late onset neonatal sepsis) & 175 & 16.81 \\
NHB(neonatal hyperbilirubinemia) & 241 & 23.15 \\
Prematurity & 99 & 9.51 \\
LBW(low birth weight) & 83 & 7.97 \\
VLBW(very low birth weight) & 11 & 1.06 \\
ELBW(extremely low birth weight) & 5 & 0.48 \\
Birth asphyxia & 95 & 9.13 \\
HIE-1 (hypoxic ischemic encephalopathy) & 72 & 6.92 \\
HIE-2 & 19 & 1.83 \\
HIE-3 & 4 & 0.38 \\
MAS(meconium aspiration syndrome) & 75 & 7.2 \\
Anomalies & 18 & 2.59 \\
IUGR(intra-uterine growth retardation) & 9 & 0.86 \\
Macrosomia & 16 & 1.54 \\
TTN(transient tachypnea of newborn) & 1.72 \\
Others & 97 \\
\hline & 97 & \\
\hline
\end{tabular}

Analysis of outcome showed that out of 1041 neonates, 831 cases $(79.83 \%)$ were improved and discharged to home, $79(7.59 \%)$ were discharged on request, 61 (5.86\%) left against medical advice, 34 (3.26) were referred and 36 $(3.46 \%)$ expired as shown in Table 4 . The main reason for referral was congenital anomalies and the surgical interventions required. The leading causes of death were prematurity 16 (44.45\%), followed by sepsis 10 (27.78\%), Perinatal asphyxia 5 (13.89\%) and meconium aspiration syndrome 2(5.55\%) [Table 5]. Among the expired neonates, 24 (66.67\%) were outborns and 12 (33.33\%) were inborns and majority 27 (75\%) expired at the age between 24 to 48 hours of life as shown in Table 4.

Table 4: Outcome of admitted newborn

\begin{tabular}{lcc}
\hline OUTCOME & Frequency & Percent \\
Improved & 831 & 79.83 \\
Discharge on request (DOR) & 79 & 7.59 \\
Leave Against Medical Advise (LAMA) & 61 & 5.86 \\
Referred & 34 & 3.26 \\
Expired & 36 & 3.46 \\
Total & 1041 & 100 \\
Age at death & Frequency & Percent \\
1-3 days & 27 & 75 \\
4-7 days & 4 & 11.11 \\
8-28 days & 5 & 13.89 \\
Inborn/outborn death & Frequency & Percent \\
Inborn & 12 & 33.33 \\
Outborn & 24 & 66.67 \\
\hline
\end{tabular}

Table 5: Causes of mortality

\begin{tabular}{lcc}
\hline Cause of mortality & Frequency & Percent \\
Prematurity & 16 & 44.45 \\
Sepsis & 10 & 27.78 \\
Asphyxia & 5 & 13.89 \\
Congenital anomalies & 2 & 5.55 \\
MAS (meconium aspiration syndrome) & 2 & 5.55 \\
HDN (hemorrhagic disease of newborn) & 1 & 2.78
\end{tabular}

\section{DISCUSSION}

This is the first clinical audit of admissions into the neonatal unit of this hospital since it was established in 2010. Total 1041 newborns were admitted in neonatology division during study period. Males were predominant in our study, which was similar to other studies ${ }^{3,9,13}$ suggesting that the male gender is more susceptible to illness during the neonatal period and male babies seek health attention with early detection of neonatal problems.

The majorities $90.49 \%$ were term gestation and $9.51 \%$ were preterm. This finding was different from other centers where the percentages of premature babies were higher ${ }^{10,13}$ and similar to the study done by Banstola R. Et al. ${ }^{3}$ Financial factor remains a reason that preterm babies are hardly brought to the hospital on time and admitted for the further management in the developing countries. Preventive measures, appropriate timing and place for referral and governmental funding should be looked into as the preterm requires prolonged hospital stay.

Our studies showed the maximum admission is in first 24 hours of life (52.83\%) which is similar to other studies where the first 24 hours of life admission ranged from $33.61 \%$ to $44.47 \%{ }^{1,14}$ The reason for high admission within the first 24 hours of life is due to the fact that this period is the most vulnerable period of life.

The leading cause of admission in the neonatal care unit at our center was infection (44.96\%), which was similar to study done by Kanodia et al ${ }^{12}$ but higher than the reports from other centres in Nepal (21.4\% to $32.6 \%) .{ }^{13}$ However, lower incidences ( 6.4 to $10.5 \%$ ) were reported by other authors in their studies. ${ }^{3,15}$ We have included all the suspected and culture proven pneumonia, meningitis, intrauterine infections and local skin infection as neonatal sepsis and it may be the factor for the higher incidence.

Neonatal hyperbilirubinemia is the second common cause of admissions in NICU and it accounts for $23.15 \%$ of admissions. Much higher incidences (36.2 to 54\%) have been re- 
ported in other studies ${ }^{16,17}$ and lower incidence in Banstola et $\mathrm{al}^{3}$ and Shrestha et al. ${ }^{18}$ However, these could have been curtailed by early detection, bilirubin monitoring and effective phototherapy and two of them underwent exchange blood transfusion.

Overall mortality observed was $3.46 \%$ and in particular, mortality was observed higher among preterm neonates followed by sepsis and birth asphyxia and more during the first 48 hours of life in our study. Mortality is low in our setup but in contrast, rate of LAMA (leave against medical advice) is high. Other studies have reported higher mortality rates (25.8-34\%) but Jan et $\mathrm{al}^{17}$ found lower mortality in their audit report. ${ }^{19}$ Yasmeen and coworkers also revealed similar figures of neonatal mortality which showed prematurity was the leading cause of death among preterm neonates, followed by asphyxia, and sepsis in their study. ${ }^{20}$ Studies conducted by Al-Turkistani and coworkers, ${ }^{21}$ Quddusi and associates ${ }^{22}$ and Kotwal and coauthors ${ }^{23}$ have revealed minimum proportion of LAMA cases at $0.2 \%$ and maximum proportion at $25.4 \%$. This proportion of LAMA cases may depend upon the availability of healthcare resources, services and socioeconomic circumstances. The mortality depends upon the stage of the disease and facilities available in a particular NICU. Moreover, attempt should be made to keep it as low as possible. Findings of this study have the limitation that certain important variables like socio-economic circumstances, data of ventilator support finding were not included. Lastly, no follow-up records could be retrieved as it was a retrospective study.

\section{CONCLUSION}

In our study sepsis, hyperbilirubinemia and prematurity were the leading causes of morbidity. Neonatal sepsis can be prevented by enforcing strict hand hygiene and aseptic protocols. Low birth weight and prematurity were the significant contributors to mortality. Hence antenatal programs to prevent prematurity and low birth weight babies should be strengthened. The higher incidence of birth asphyxia and the mortality associated with it in the outborn admissions in the present study warrants strategies to be implemented to prevent birth asphyxia in the referring centers.

\section{Conflict of interest}

None declared

\section{Acknowledgement}

We thank all the medical officers of the department of the pediatrics and the nursing staff of NICU.

\section{REFERENCES}

1. Jehan I, Harris H, Salat S, Zeb A, Mobeen N, Pasha O, et al. Neonatal mortality, risk factors and causes: a prospective population-based cohort study in urban Pakistan. Bull World Health Organ. 2009 Feb;87(2):130-8. DOI: 10.2471/ BLT.08.050963 PMID: 19274365.

2. Aurangzeb B, Hameed A. Neonatal sepsis in hospital born babies: bacterial isolates and antibiotic susceptibility patterns. J Coll Physicians Surg Pak. 2003 Nov;13(11):629-32. PMID:14700488.

3. Banstola R, Shrestha S, Ghimire J, Gurung R, Sigdel Y. Disease Pattern and Outcome of Neonates at Special Newborn Care Unit (SNCU) of Pokhara Academy of Health Science (PAHS), Nepal. Nepal Journal of Obstetrics and Gynaecology. 2018;12(2):61-4. DOI: 10.3126/njog.v12i2.19956

4. Khinchi YR, Kumar A, Yadav S. Profile of Neonatal sepsis. Journal of College of Medical Sciences-Nepal. 2010;6(2):1-6. DOI: $10.3126 /$ jcmsn.v6i2.3609

5. Miles M, Dung KTK, Ha LT, Liem NT, Ha K, Hunt RW, et al. The cause-specific morbidity and mortality, and referral patterns of all neonates admitted to a tertiary referral hospital in the northern provinces of Vietnam over a one year period. Plos One. 2017;12(3):1-12. DOI: 10.1371/ journal.pone.0173407 PMID: 28282433.

6. Afshan K, Narjis G, Qureshi IZ, Cappello M. Social determinants and causes of child mortality in Pakistan: Analysis of national demographic health surveys from 1990 to 2013. J Paediatr Child Health. 2020;56(3):457-72. DOI: 10.1111/ jpc.14670 PMID: 31774227.

7. Ibrahim RM, Hashem BJ. The outcome of newborn admitted in neonatal care unit, center teaching hospital of pediatric, Baghdad Al-krakh, 2015. Al-Kindy Coll Med J. 2019;15(1):4351. DOI: $10.47723 / \mathrm{kcmj} . v 15 \mathrm{i} 1.77$

8. Ministry of Health and Population (MOHP) [Nepal], New ERA, ICF International Inc. Nepal Demographic and Health Survey 2016. Kathmandu, Nepal: Ministry of Health and Population, New ERA, ICF International; 2017.

9. Shakya A, Shrestha D, Shakya H, Shah SC, Dhakal AK. Clinical profile and outcome of neonates admitted to the Neonatal Care Unit at a teaching hospital in Lalitpur, Nepal. J Kathmandu Med Coll. 2015;3(4):144-8. DOI: 10.3126/jkmc. v3i4.13370

10. Gurubacharya S, Gurubacharya R. An Overview of Neonatal Admissions at College of Medical Sciences (COMS). Journal of Nepal Paediatric Society. 2009;27(2):73-74. DOI: 10.3126/ jnps.v27i2.1413

11. Shah GS, Yadav S, Thapa A, Shah L. Clinical profile and outcome of neonates admitted to (NICU) at a tertiary care 
neonatal intensive care unit centre in eastern Nepal. J Nepal Paediatr Soc. 2013;33(3):177-81. DOI: 10.3126/jnps. v33i3.8447

12. Kanodia P, Yadav SK, Bhatta NK, Singh RR. Disease profile and Outcome of Newborn admitted to Neonatology unit of BPKIHS. J Coll Med Sci. 2015;11(3):20-4. DOI: 10.3126/ jcmsn.v11i3.14059

13. Tanveer S, Basheer F, Motlaq FMA, Khushdil A, Nawaz R, Khan FA. Pattern of admission and outcome of neonates admitted to tertiary care neonatal ICU. Journal of Fatima Jinnah Medical University. 2019;13(3):116-20. DOI: 10.37018/ jfjmu.v13i3.638

14. Hoque M, Haaq S, Islam R. Causes of neonatal admissions and deaths at a rural hospital in kwazulu-Natal, South Africa. South African J Epidemiol Infect. 2011;26(1):26-9. DOI: 10.1080/10158782.2011.11441416

15. Anurekha V, Kumaravel KS, Kumar P, Satheesh Kumar D. Clinical profile of neonates admitted to a neonatal intensive care unit at a referral hospital in South India. Int J Pediatr Res. 2018;5(2):72-77. DOI: 10.17511/ijpr.2018.i02.06

16. Shahidullah M, Hasan MZ, Jahan I, Ahmed F, Dey AC, Dey SK, et al. Perinatal Characteristics and Outcome of Neonates at NICU of a Tertiary Level Hospital in Bangladesh. Bangladesh J Child Heal. 2017;41(1):34-9. DOI: 10.3329/bjch. v41i1.33634

17. Jan AZ, Ahmad S, Zahid SB. Clincal Audit of Admission Pat- tern and Its Outcome in a Neonatal Icu. Gomal J Med Sci. 2013;11(1):11-6.

18. Shrestha S, Sindan N, Kayastha N, Karki D, Jha K, Thapa S, et al. Clinical profile and outcome of neonates admitted to the Neonatal Care Unit in a rural teaching Hospital. Journal of Karnali Academy of Health Sciences 2018 Oct 6; 1(02):23-7.

19. Narayan R. A study of pattern of admission and outcome in a neonatal intensive care unit at high altitude. Sri Lanka J Child Health. 2012;41:79-81. DOI:10.4038/ sljch.v41i2.4396

20. Yasmeen S, Irfan Waheed KA, Gul R. Spectrum of neonatal admissions and their outcome in a tertiary care hospital. Pakistan Paediatr J. 2018;42(1):8-9.

21. Al-Turkistani H. Discharge against medical advice from Neonatal Intensive Care Unit: 10 years' experience at a University Hospital. J Fam Community Med. 2013;20(2):113. DOI: 10.4103/2230-8229.114774

22. Quddusi AI, Razzaq A, Hussain S, Hussain A. Pattern of neonatal admission at the Children's Hospital and the Institute of Child Health, Multan. J Ayub Med Coll Abbottabad. 2012;24(2):108-10. PMID: 24397068.

23. Singh YK, Yatoo GH, Ahmed Jan F. Morbidity and Mortality Among Neonates Admitted to a Neonatal Intensive Care Unit of a Tertiary Care Teaching Hospital of Jammu and Kashmir (India). Neonatal Pediatr Med. 2017;03:136. DOI: 10.4172/2572-4983.1000136 